\title{
Capillary blood sampling: should the heel be warmed?
}

\author{
D P Barker, B Willetts, V C Cappendijk, N Rutter
}

\begin{abstract}
The hypothesis that capillary blood sampling is made easier by warming the heel was examined in a randomised, controlled trial of healthy newborn infants. Sampling was performed using an automated lancet with or without prior warming. The time taken to collect a standard volume of blood, the number of repeat procedures needed, and the infants' behavioural responses were measured. Eighty one procedures were studied in 57 infants. Warming produced a median rise in heel skin temperature of $4 \cdot 7^{\circ} \mathrm{C}$. However, there were no significant differences between the warmed and unwarmed groups in any of the outcome measures.
\end{abstract}

Heel skin temperature is not an important factor in capillary blood sampling. Attention should be directed towards nique.

(Arch Dis Child 1996; 74: F139-F140)

Keywords: heel, capillary blood sampling, pain, temperature.

Heel blood sampling is the most frequently performed invasive procedure in the newborn period. ${ }^{1}$ It is acknowledged to be painful, ${ }^{2}$ and recent research has focused on ways of obtaining samples more humanely. ${ }^{3-4}$ Prewarming the heel to increase blood flow is recommended as part of heel preparation ${ }^{6}$ but is not widely practised. If effective, warming should benefit infants by reducing the amount of squeezing required and the need for repeat punctures, so that the procedure is completed more quickly.

A pilot study was performed in 42 healthy infants (below 2 weeks of age) to investigate the relation between heel skin temperature and the time taken to collect a standard volume of blood. We were surprised to find that over a temperature range of $27-35^{\circ} \mathrm{C}$ sampling time was independent of skin temperature. To further investigate this, we designed a study to examine the effect of active warming upon ease of sampling.

Neonatal Medicine and Surgery, Nottingham City Hospital, Nottingham

D P Barker

B Willetts

V C Cappendijk

N Rutter

Correspondence to: Dr Barker, Department of Child Health, E Floor, East Block, Queen's Medical Centre, Nottingham, NG7 2UH.

Accepted 20 October 1995

\section{Methods}

The study took place on the postnatal wards of Nottingham City Hospital over one month. Healthy newborn infants requiring blood sampling for Guthrie screening or bilirubin measurement were randomly allocated to sampling with or without prior warming. Fifty seven infants (27 girls), of median gestation 39 improving sampling devices and tech-

weeks (range 35 to 41 ), median birthweight $3.3 \mathrm{~kg}$ (range 2.46 to 4.92 ), and median postnatal age 5 days (range 0 to 8 ) were recruited to the study. Most $(43 / 57,75 \%)$, were studied once only. The remainder were randomised on each occasion, with the second and any subsequent samples collected on separate days.

Warming was performed using a gel pack specifically designed for this purpose (Tendertherm Infant Heel Warmer, Prism Technologies, Inc, San Antonio, Texas). The gel is activated to an initial temperature of $40^{\circ} \mathrm{C}$ by bending a metal disc located within it, and the pack is then folded around the planter surface of the foot, secured with an adhesive strip, and left for 10 minutes.

Heel skin temperature was measured using a fine thermocouple thermometer probe (Comark microprocessor thermometer, type No 6600). Two measurements were taken in the warmed group (before and after) and a single measurement in the unwarmed group. All samples were collected using an automated lancet (Autolet Lite Clinisafe, Owen Mumford, Oxford) by a single researcher (DPB), who was unaware of the temperature reading. Samples collected were of standard volume $(0.15 \mathrm{ml}$, equivalent to two small capillary tubes). The infants' behavioural response to firing of the device was observed (recorded as presence or absence of facial grimacing and cry), and the time taken to complete sample collection, and occasions on which repeat procedures were required were noted. The study was conducted with the approval of the hospital ethical committee, and maternal consent was obtained for each infant.

\section{Results}

Eighty one procedures were performed, 70 $(86 \%)$ in term infants. Forty one specimens were collected after warming and 40 without warming. There were no significant differences in gestation, birthweight, or postnatal age among infants whose samples were collected with or without warming (Mann-Whitney U test). The median heel skin temperature from unwarmed heels was $30.8^{\circ} \mathrm{C}$ (range 28.1 to $34 \cdot 8)$. In the warmed group a similar initial

Sampling time and repeat procedures

\begin{tabular}{|c|c|c|}
\hline & $\begin{array}{l}\text { Sampling time (seconds) median } \\
\text { (interquartile range) }\end{array}$ & $\begin{array}{l}\text { No of repeats } \\
\text { (\%) }\end{array}$ \\
\hline $\begin{array}{l}\text { Unwarmed } \\
\text { Heels }(n=40) \\
\text { Warmed } \\
\text { Heels }(n=41)\end{array}$ & $\begin{array}{l}40 \\
(28 \text { to } 72) \\
44^{\star} \\
(25 \text { to } 62)\end{array}$ & $\begin{array}{l}8 / 40 \\
(20 \%) \\
5 / 41^{\star} \\
(12 \%)\end{array}$ \\
\hline
\end{tabular}




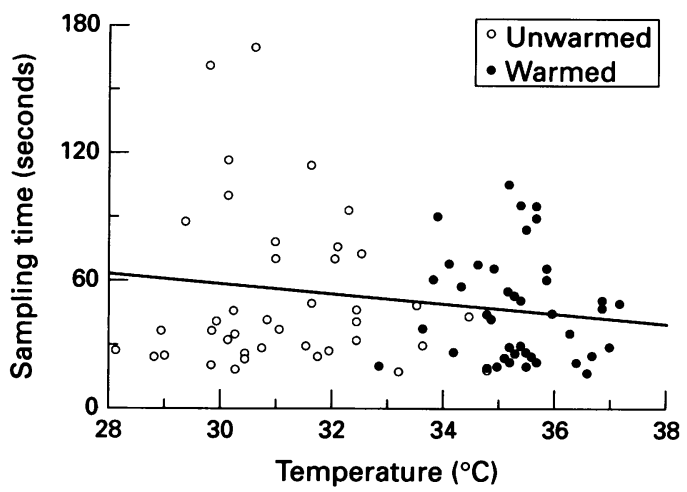

Sampling time vs heel skin temperature (Spearman rank correlation coefficient Rho $=-0.06, P=0.56)$.

temperature range was observed (median $30.5^{\circ} \mathrm{C}$, range $27 \cdot 7$ to $34.6^{\circ} \mathrm{C}$ ), rising after warming to a median of $35.3^{\circ} \mathrm{C}$ (range 32.8 to $37 \cdot 2^{\circ} \mathrm{C}$ ), a median increase of $4 \cdot 7^{\circ} \mathrm{C}$ (range $1 \cdot 7$ to $6.9^{\circ} \mathrm{C}$ )

Facial grimacing was observed on $80 \%$ of occasions when the device was fired, regardless of whether warming had been performed. Grimacing was combined with a cry in a slightly higher proportion of infants in whom warming had been performed (14/41 (34\%) vs $10 / 40(25 \%)$, but this difference was not significant ( $\chi^{2}$ test).

The table shows the median sampling times for warmed and unwarmed heels, which did not differ significantly (Mann-Whitney U test). Similarly, the number of repeat procedures required did not differ significantly between groups ( $\chi^{2}$ test). The correlation between heel skin temperature and sampling time is shown in the figure. No significant correlation was found between these variables (Spearman rank correlation coefficient Rho $=-0.06 ; P=0.56$ ).

\section{Discussion}

Skin temperature is one of several potentially important factors in heel blood sampling. Others include the required blood volume, the type and penetration depth of the device used, and the experience and technique of the operator. In this controlled study our findings do not support the widely held belief that warming the heel is effective in improving blood flow. Sampling time and the number of repeat procedures did not differ significantly between warmed and unwarmed heels, and the correlation between sampling time and heel temperature was weak.

Skin temperature is commonly used as an index of perfusion. Studies using laser Doppler flowmetry have examined the relation between skin blood flow and the thermal environment in preterm and term infants. ${ }^{78}$ Increases in skin blood flow with warming have been attributed to the combined effect of increased flow in arteriovenous shunts and capillaries. These studies were not performed at peripheral sites, however, where in the newborn infant sluggish blood flow can result in peripheral cyanosis for several days after birth. Important differences may exist in the control of peripheral skin blood flow between the newborn and older infants and children.

The automated lancet used in this study penetrates the skin to a depth of $2.4 \mathrm{~mm}$. At this depth, which is the maximum recommended, ${ }^{9}$ the dermal capillary bed is pierced rather than deeper arterioles or venules. There is evidence that blood flow in this capillary bed is unaffected by temperature over the range of peripheral skin temperatures found in healthy mature newborn infants. Norman et al used videophotometric microscopy to examine capillary blood flow. ${ }^{10}$ No correlation was found between capillary blood cell velocity and skin temperature over the range 27 to $33^{\circ} \mathrm{C}$. Our failure to find a significant corelation between sampling time (used as an index of blood flow) and heel temperature agrees with their findings. Additional evidence comes from a study of capillary blood sampling (using an Autolet device) in preterm infants, in which heel warming had no effect on the discrepancy between arterial and capillary $\mathrm{PO}_{2}$ values. ${ }^{11}$ Any increase in skin blood flow with temperature appears to be derived from deeper thermoregulatory vessels rather than more superficial capillaries.

We propose that skin temperature is not an important factor in heel blood sampling, and that to minimise the trauma and distress caused to infants more attention should be directed towards other factors, such as sampling devices and technique.

1 Barker DP, Rutter N. Exposure to invasive procedures in neonatal intensive care unit admissions. Arch Dis Child 1995; 72: F47-8

2 Owens ME, Todt EH. Pain in infancy: neonatal reaction to a heel lance. Pain 1984; 20: 77-86.

3 Haouari N, Wood C, Griffiths G, Levene M. The analgesic effect of sucrose in full term infants: a randomised coneffect of sucrose in full term infants: a

4 McIntosh N, van Veen L, Brameyer $H$. Alleviation of the pain of heel prick in preterm infants. Arch Dis Child 1994; 70: F177-81.

5 Short BL. Capillary blood sampling. In: Fletcher MA, MacDonald MG, eds. Atlas of procedures in neonatology. Philadelphia: J B Lippincott Co, 1993: 97-100.

6 Meites S. Skin-puncture and blood-collecting technique for infants: update and problems. Clin Chem 1988; 34: 1890-4.

7 Beinder E, Trodan A, Bucher HU, Huch A, Huch R Control of skin blood flow in pre- and full-term infants. Biol Neonate 1994; 65: 7-15.

8 Suichies HE, Brouwer C, Aarnoudse JG, Jentink HW, de Mul FFM, Greve J. Skin blood flow changes, measured by laser doppler flowmetry, in the first week after birth. Early

9 Blumenfeld TA, Turi GK, Blanc WA. Recommended site and depth of newborn heel skin punctures based on anatomical measurements and histopathology. Lancet 1979; i: $230-3$.

10 Norman M, Herin P, Fagrell B, Zetterstrom R. Capillary blood cell velocity in full-term infants as determined in skin by videophotometric microscopy. Ped Res $1988 ; 23: 585-8$.

11 McLain BI, Evans J, Dear PRF. Comparison of capillar and arterial blood gas measurements in neonates. Arch Dis Child 1988; 63: 743-7. 